\title{
Feasibility and impact of laparoscopic sleeve gastrectomy after renal transplantation on comorbidities, graft function and quality of life
}

Naif A. AlEnazi ${ }^{*}$, Khaled S. Ahmad ${ }^{1}$, Ilham A. Elsamahy² and Mohamed S. Essa ${ }^{3}$

\begin{abstract}
Background: The aim of this study is to clarify the feasibility and effect of laparoscopic sleeve gastrectomy (LSG) on comorbidities, graft function and quality of life in patients who underwent renal transplantation (RT).

Methods: This is a retrospective review of five patients who underwent LSG after RT. Demographic data, anthropometric parameters, the effect on comorbidities, postoperative course, immunosuppressive medications, causes of $R T$, renal function, the survival of graft, and quality of life after SG in obese patients with a history of RT were assessed using BAROS-Moorhead-Ardelt survey

Results: From September 2015 to September 2019, 5 renal transplant patients underwent LSG; three female, and two male. Median body mass index (BMI) decreased from $42.17 \mathrm{~kg} / \mathrm{m}^{2}$ (range 36-55) before surgery to $28.16 \mathrm{~kg} / \mathrm{m}^{2}$ (range 25-42) after surgery. Improvement in blood pressure, triglyceride, and cholesterol levels was observed, and all cases were able to decrease their medications. Insulin was stopped and replaced with linagliptin in all diabetic patients. Graft function improved, and proteinuria level decreased in all cases. All patients reported to have an excellent quality of life.
\end{abstract}

Conclusion: LSG showed excellent outcomes in this high-risk group of patients regarding comorbidities, graft function and quality of life

Keywords: Renal transplantation, Sleeve gastrectomy, Hypertension, Dyslipidemia, Graft function

\section{Background}

Obesity has a strong relationship with hypertension (HTN) and type 2 diabetes (T2D), which are essential risk factors that lead to end-stage renal disease (ESRD). Furthermore, HTN and T2D are the most common causes of chronic kidney disease (CKD). It is noted that CKD is continually increasing at a rate of $7 \%$ per year.

\footnotetext{
*Correspondence: dr.naifalenazi@gmail.com

1 Department of General Surgery, Ad Diriyah Hospital, Ar Rihab, Riyadh, Saudi Arabia

Full list of author information is available at the end of the article
}

Interestingly, BMI has increased in CKD patients undergoing dialysis and also in patients on the waiting list for RT [1-6]. Several centers consider transplantation is contraindicated in morbidly obese patients because it is associated with a high rate of morbidity $[7,8]$.

Weight gain and morbid obesity following renal transplantation are considered a major health concern [9]. Multiple factors may provoke post-renal transplant weight gain, including immunosuppressant, hormonal changes, and lack of physical activity [10, 11]. Obesity has a significant burden on both pre- and post-transplantation patients, including a high risk of graft loss and 
delayed graft function [12]. Obesity can negatively influence wound repair and increase the risk of postoperative hernias [13]. Also, it is associated with shortening patient survival and decreased quality of life [12, 13]. Bariatric surgery, especially LSG, is effective in reducing weight and obesity-related complications among post-renal transplantation population $[14,15]$. Nonetheless, the efficacy of LSG for post-renal transplantation patients has not been thoroughly investigated. This case series retrospectively reviews and highlights the outcomes of five patients who underwent LSG following a kidney transplant.

\section{Methods}

This study involves 5 patients who underwent LSG postRT from September 2015 to September 2019. The data of the patients were assessed retrospectively after approval by institutional review board (IRB) of Saudi German Hospital (No.17918). Data regarding patients' age, gender, medical history, operative time, timing from RT to LSG and BMI before RT and LSG and after LSG were assessed. Graft function and survival (defined as no clinical or laboratory evidence of graft rejection) associated with post-RT sleeve gastrectomy for obese patients were assessed. Both graft function and survival were assessed by serum creatinine level, urine protein level, and urine output every 3,6 , 9, 12 months after surgery, then every year during a followup period. BAROS-Moorhead-Ardelt score was used for the evaluation of the quality of life before surgery and 1 year after surgery. This score assesses the percentage of excess weight loss (\%EWL), comorbidities resolution, and quality of life score from 1 to 9. BAROS-Moorhead-Ardelt score is: failure $(\leq 1)$, fair enough $(1-3)$, good results ( $(3-5)$, very good ('5-7), and excellent (>7-9) [16]. \%EWL calculated by dividing the number of kilograms lost by the number of kilograms in excess body weight (EBW) of the patient. \%EWL measured 3, 6, 9, 12 months after surgery then yearly.

\section{Exclusion criteria}

The following patients were excluded from the study: (1) age $<18$ years old, (2) Simultaneous non-renal transplant, (3) Previous non-renal transplant, (4) Primary non-functioning graft AND (5) Data regarding BMI at the time of transplant not available.

\section{Outcomes}

Primary outcome includes impact of LSG on \%EWL and graft function while secondary outcome is impact of LSG on comorbidities and medications.

\section{Follow up}

Postoperative clinical follow-up was done every 3 months in the first year, then yearly, and included, history and physical examination, calculation of \%EWL in addition to checking of creatinine level and urine protein level.

\section{Surgical technique}

Under direct vision, 12-mm optical trocar was inserted for the camera in the midline supraumbilical position. After that, two other ports were inserted (one $5 \mathrm{~mm}$ on the left hypochondrium and one $5 \mathrm{~mm}$ on the right hypochondrium) in addition to a $10-\mathrm{mm}$ trocar that was inserted on the left flank. PretzelFlex liver retractor was introduced in the epigastric region. Dissection of the greater omentum and short gastric vessels from the gastric greater curvature till the left crus of the diaphragm using Harmonic scalpel. A 42-Fr bougiewas inserted. Gastric divison started approximately $4-6 \mathrm{~cm}$ from the pylorus and parallel to the lesser curvature of the stomach and extended vertically toward His angle using between 4 and 5 linear staplers such as Echelon 60 . Black $(4.2 \mathrm{~mm})$, green $(4.1 \mathrm{~mm})$, gold $(3.8 \mathrm{~mm})$, or blue $(3.5 \mathrm{~mm})$ cartridges were applied based on the gastric wall thickness. The reinforcement of the staple line was done using an absorbable suture in running fashion. The specimen was retrieved in a plastic bag.

\section{Results}

This study included five patients who underwent postRT laparoscopic sleeve gastrectomy between September 2015 and September 2019. There were three females and two males. The median BMI before RT was $29.24 \mathrm{~kg} /$ $\mathrm{m}^{2}$ (range 22-41) and before SG was $42.17 \mathrm{~kg} / \mathrm{m}^{2}$ (range 36-55). Demographic data, comorbidities, timing from RT to LSG, and operative duration are shown in (Table 1). Anthropometric parameters pre-RT, pre-SG, and post-SG are shown in (Table 2). The median followup period was 24 months (range 7-48). At that time, the median BMI was $28.45 \mathrm{~kg} / \mathrm{m}^{2}$ (range 25-42), and \%EWL was $56.4 \%$ (range 31-86) (Fig. 1). Associated comorbidities were HTN and dyslipidemia (DSL) in all patients. Three patients had T2D, and 2 had gout.

Regarding comorbidities, the results were as follows: improvement in blood pressure occurred in of patients from 145 to $155 / 89-100 \mathrm{mmHg}$ LSG to $120-130 / 70$ $90 \mathrm{mmHg}$ after LSG $(p=0.263)$. Also, a reduction in cholesterol level has been observed; the median cholesterol level was reduced from $332 \mathrm{mg} / \mathrm{dl}$ (range 315-356) before the surgery to $216 \mathrm{mg} / \mathrm{dl}$ (range 192-220) after surgery $(\mathrm{p}=0.247)$. The median Triglycerides level reduced from $200 \mathrm{mg} / \mathrm{dl}$ (range 195-240) to $155 \mathrm{mg} / \mathrm{dl}$ (range 125-170) $(p=0.196)$ (Table 3). Regarding diabetes mellitus (DM), 3 patients were T2D. All were receiving Novomix insulin (2 patients received Novomix 40U/day, and 1 patient Novo$\operatorname{mix} 60 \mathrm{U} /$ day) before surgery. After surgery, linagliptin $(5 \mathrm{mg} /$ day) replace insulin in all cases. The median A1C 
Table 1 Demographic data, comorbidities, timing fromRT to LSG and operative time

\begin{tabular}{lllllc}
\hline Number & Age (years) & Sex & Medical history & $\begin{array}{l}\text { Time from RT to LSG } \\
\text { (years) }\end{array}$ & $\begin{array}{l}\text { Operative } \\
\text { time (min) }\end{array}$ \\
\hline Patient 1 & 40 & Male & HTN, Dyslipidemia, Gout & 6 & 62 \\
Patient 2 & 52 & Female & HTN, DM, dyslipidemia & 6 & 58 \\
Patient 3 & 33 & Female & HTN, Dyslipidemia, DM & 4 & 65 \\
Patient 4 & 38 & Male & HTN, dyslipidemia & 3 & 50 \\
Patient 5 & 36 & Female & HTN, DM, dyslipidemia & 9 & 70 \\
\hline
\end{tabular}

HTN hypertension, DM diabetes mellitus, LSG laparoscopic sleeve gastrectomy, BMI body mass index, min minute

Table 2 Anthropometric parameters

\begin{tabular}{ll}
\hline Anthropometric data & $\begin{array}{l}\text { Median } \\
\text { (range) }\end{array}$ \\
\hline BMl before RT $\left(\mathrm{kg} / \mathrm{m}^{2}\right)$ & $29.24(22-41)$ \\
BMl before LSG $\left(\mathrm{kg} / \mathrm{m}^{2}\right)$ & $42.17(36-55)$ \\
Weight before $L S G(\mathrm{~kg})$ & $112(92-130)$ \\
BMl after LSG $\left(\mathrm{kg} / \mathrm{m}^{2}\right)$ & $28.45(25-42)$ \\
Follow-up after LSG (months) & $24(7-48)$ \\
\hline
\end{tabular}

$R T$ renal transplantation, $L S G$ laparoscopic sleeve gastrectomy, BMI body mass index

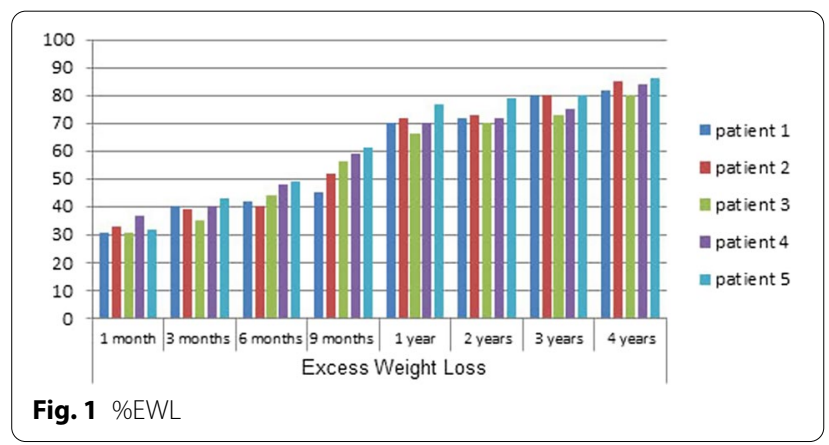

reduced from 8 before LSG to 6.2 after LSG at 48 months follow-up period (Table 4).

Before RT, all patients were on hemodialysis. PostRT, all cases received immunosuppressive medications: steroids and cyclosporine were given for all patients. In addition, 4 patients received mycophenolate, 1 patient azathioprine, 1 patient tacrolimus, and 1 patient everolimus. Indications for RT were systemic lupus erythematosus (SLE), HTN, DM, interstitial nephritis and glomerulonephritis. The median time between RT and LSG was 4 years (range 3-9). The median operative duration for LSG was 65 min (range 50-70). The median length of hospital stay was 5 days (range 4-6). Postoperative recovery was uneventful. There were no complications or mortality after surgery in this series.

The median creatinine level was $1.6 \mathrm{mg} / \mathrm{dl}$ (range 1.22.2) preoperatively, after LSG, it decreased to $1.18 \mathrm{mg} /$ $\mathrm{dl}$ (range 0.9-1.5) $(p=0.253)$, creatinine levels improved in all cases (Fig. 2). The median protein level in urine decreased from $30 \mathrm{mg} / \mathrm{dl}$ (range 10-37) before the surgery to $12 \mathrm{mg} / \mathrm{dl}$ (range $8-18)$ after surgery $(p=0.261)$. As creatinine levels, protein levels in urine decreased in all patients post-LSG.

All patients reported an excellent quality of life after surgery, the median BAROS-Moorhead-Ardelt score before LSG was 1 (range 1-3) and after LSG was 7 (range 7-9). They were satisfied with the results after surgery.

\section{Discussion}

Weight gain and obesity are common conditions affecting around half of the post-kidney transplant patients. Post-grafting weight gain is associated with the incidence of hypertension, diabetes mellitus, hyperlipidemia, graft rejection, and decreased graft survival $[4,17]$. Curran et al., reported that patients with $B M I \geq 30 \mathrm{~kg} / \mathrm{m}^{2}$ at the time of transplant was associated with high risks

Table 3 Evolution in cholesterol, triglyceride and blood pressure post-SG

\begin{tabular}{lllllll}
\hline Comorbidities & & Patient 1 & Patient 2 & Patient 3 & Patient 4 & Patient 5 \\
\hline Cholesterol (mg/dl) (median) & Pre-SG & 345 & 328 & 332 & 315 & 356 \\
& Post-SG & 210 & 205 & 216 & 192 & 220 \\
Triglycerides (mg/dl) (median) & Pre-SG & 240 & 220 & 200 & 197 & 195 \\
& Post-SG & 170 & 160 & 150 & 155 & 125 \\
Blood pressure (mmHg) & Pre-SG & $150-155 / 90-94$ & $145-150 / 95-100$ & $149-155 / 90-95-$ & $150-155 / 89-95$ & $145-150 / 95-100$ \\
& Post-SG & $120-125 / 80-85$ & $125-130 / 80-90$ & $125-130 / 75-80$ & $120-130 / 80-85$ & $125-130 / 70-78$ \\
\hline
\end{tabular}

$S G$ sleeve gastrectomy 
Table 4 Improvement in A1C and medications after SG

\begin{tabular}{|c|c|c|c|c|}
\hline Patients & Type of DM & Timing & A1C & Medications \\
\hline \multirow[t]{2}{*}{ Patient 2} & $\mathrm{~T} 2 \mathrm{D}$ & Pre-LSG & 8.6 & Biphasic insulin 70:30 (Novomix) $40 \mathrm{U}$ daily \\
\hline & & Post-LSG & 6.4 & Linagliptin 5 mg/day \\
\hline \multirow[t]{2}{*}{ Patient 3} & $\mathrm{~T} 2 \mathrm{D}$ & Pre-LSG & 8 & Biphasic insulin 70:30 (Novomix) $40 \mathrm{U}$ daily \\
\hline & & Post-LSG & 6.2 & Linagliptin 5 mg/day \\
\hline \multirow[t]{2}{*}{ Patient 5} & $\mathrm{~T} 2 \mathrm{D}$ & Pre-LSG & 9 & Biphasic insulin 70:30 (Novomix) $60 \mathrm{U}$ daily \\
\hline & & Post-LSG & 6.7 & Linagliptin 5 mg/day \\
\hline
\end{tabular}

T2D diabetes mellitus type2, $A 1 C$ glycosylated hemoglobin, LSG laparoscopic sleeve gastrectomy

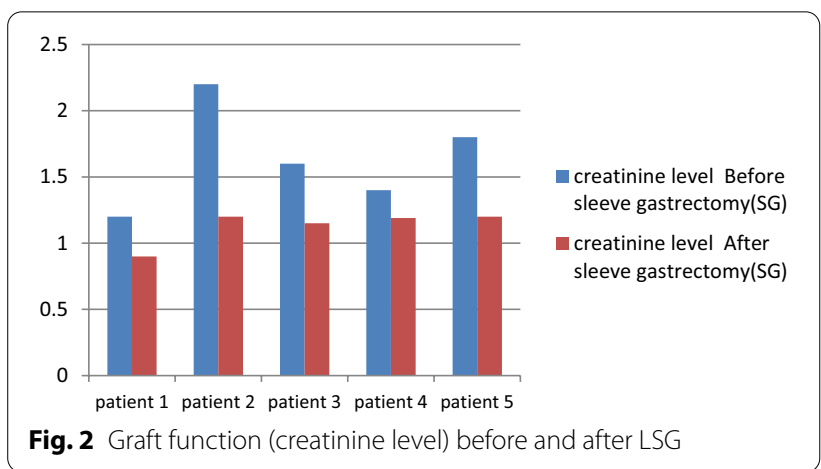

of delayed graft function (DGF) while patients with a $\mathrm{BMI} \geq 35 \mathrm{~kg} / \mathrm{m}^{2}$ were at greater risks of biopsy-proven acute graft rejection (BPAR) and all-cause graft failure [18]. Thus, effective weight reduction procedures are essential to preclude these complications. Bariatric surgery is an effective ingrained management choice for morbid obesity in particular cases [14]. Of note, LSG, compared to other bariatric operations, has promising efficacy and reliability $[14,15]$.

The American Society of Metabolic and Bariatric Surgery (ASMBS) has approved the LSG as the first-stage procedure for sustained weight reduction in 2012 [19]. Previous reports have indicated that LSG has several salutary features including short operative time, short hospital stay, good short-term outcomes regarding \%EWL and disappearance and/or improvement of comorbidities. In addition, and in case of failure, it can be converted to another bariatric procedure with low morbidity and mortality. It is considered a non-complex procedure compared to gastric bypass. Therefore, these advantages are of the greatest value for patients who are primarily liable to the incidence of complications [19-26].

Furthermore, LSG has been considered as the firstchoice intervention for pre-transplant candidates, as well as the post-liver transplant population [27, 28]. Thus, we believe that LSG is the proper decision for morbid obesity and weight reduction in post-renal transplant patients. A major advantage of LSG is that it does not interfere with the absorption of immunosuppressant drugs [29]. These drugs play an intrinsic role in preventing acute graft rejection and lengthening the graft survival. In contrast, malabsorptive procedures such as Roux-en- $Y$ gastric bypass (GB) and biliopancreatic diversion may manipulate the pharmacokinetics of immunosuppressant drugs. This has been stated in Golomb et al. study, whereas two patients required a higher dose of tacrolimus while the dose was decreased in one patient [30].

LSG also improves transplant eligibility by decreasing $\mathrm{BMI}$ in renal transplant candidates and prevent development of new onset DM after transplantation (NODAT). Kim Y et al., reported 20 patients underwent LSG before $\mathrm{RT}$ and compared with similar-BMI recipients who did not underwent LSG using signed-rank and McNemar's tests. In comparison to patients without LSG, Patients with post-LSG RT had lower rates of DGF (5\% vs $20 \%$ ) and graft dysfunction -related readmissions $(10 \%$ vs $27.5 \%)(\mathrm{p}<0.05$ for both) in addition to no patients developed NODAT. These results suggest that LSG for obese patients with ESRD result in improvement in transplant candidacy and post-transplantation outcomes [31].

Golomb et al. performed LSG for 10 post-renal transplant patients and concluded a successful procedure in $80 \%$ of cases without graft rejection or dysfunction [17]. Also, urinary protein and serum creatinine markedly decline following LSG, which is consistent with our findings as well as previously published reports [30-32]. In another recent study, creatinine levels were normalized following bariatric surgery, and kidney function slightly improved 12 months after surgery. The exact value and impact of this improvement have not yet clearly understood [33]. However, proteinuria has been recognized as a poor prognostic marker and risk factor of mortality among kidney transplant patients [34]. Thus, it is plausible that this improvement might have a long-term effect on graft function and survival [30].

This retrospective case series had several limitations. First, it included only five subjects that encountered the generalization and reliability of LSG as a standard measure for weight reduction in kidney transplant patients. Second, the follow-up extended to 4 years; 
however, it may not be sufficient to examine graft function and graft survival accurately. Therefore, our findings need to be further advocated by large-scale random studies with extended follow-up. Also, future studies are recommended to compare their inferences with kidney transplant patients who were not subjected to bariatric surgery.

\section{Conclusion}

Our study showed that there were no pre- or postoperative complications reported. Diabetes and hypertension were managed, and the patients discontinued the medications after bariatric surgery. Urinary proteins and lipid levels were settled, graft function was improved, and all patients reported enhanced quality of life.

\section{Abbreviations}

RT: Renal transplantation; LSG: Laparoscopic sleeve gastrectomy; SG: Sleeve gastrectomy; HTN: Hypertension; DSL: Dyslipidemia; BMI: Body mass index; ESRD: End stage renal disease; CKD: Chronic kidney disease; DM: Diabetes mellitus; T2D: Diabetes mellitus type 2; A1C: Glycosylated hemoglobin; GB: Gastric bypass; ASMBS: American Society of Metabolic and Bariatric Surgery; DGF: Delayed graft function; BPAR: Biopsy proven acute rejection; NODAT: New onset diabetes mellitus after transplantation.

\section{Acknowledgements}

Not applicable.

\section{Authors' contributions}

NA: study concept, design, data collection, interpretation, literature review, writing. KA: data collection, writing. ME: literature review, writing. IE: literature review, writing. All authors have read and approved the manuscript.

\section{Funding}

There are no sources of funding to acknowledge.

\section{Availability of data and materials}

All data generated or analyzed during this study are included in this published article and it is available from the corresponding author on reasonable request.

\section{Declarations}

\section{Ethics approval and consent to participate}

This data collection was approved by the Ethical Committee at Saudi German Hospital. IRB NO: 17918. Written informed consent was obtained from all patients to participate in the study.

\section{Consent for publication}

Written informed consent was obtained from all patients for publication of this case series including patients' information.

\section{Competing interests}

There is no conflict of interest to disclose.

\section{Author details}

'Department of General Surgery, Ad Diriyah Hospital, Ar Rihab, Riyadh, Saudi Arabia. ${ }^{2}$ Department of Anesthesia, Islamic Center for Heart Diseases and Cardiac Surgeries, Faculty of Medicine, El-Azhar University, Cairo, Egypt. ${ }^{3}$ Department of General Surgery, Faculty of Medicine, Benha University Hospital, Benha University, Benha, Egypt.
Received: 8 March 2020 Accepted: 9 March 2021

Published online: 04 May 2021

\section{References}

1. Wickman C, Kramer H. Obesity and kidney disease: potential mechanisms. SeminNephrol. 2013;33(1):14-22.

2. Kramer HJ, Saranathan A, Luke A, et al. Increasing body mass index and obesity in the incident ESRD population. J Am SocNephrol. 2006;17(5):1453-9.

3. Ejerblad E, Fored CM, Lindblad P, et al. Obesity and risk for chronic renal failure. J Am SocNephrol. 2006;17(6):1695-702.

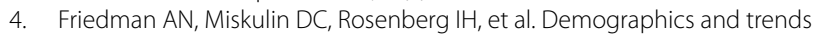
in overweight and obesity in patients at time of kidney transplantation. Am J Kidney Dis. 2003;41(2):480-7.

5. Imes CC, Burke LE. The obesity epidemic: the United States as a cautionary tale for the rest of the world. Curr Epidemiol Rep. 2014;1 (2):82-8.

6. Lysaght MJ. Maintenance dialysis population dynamics: current trends and long-term implications. J Am Soc Nephrol. 2002;13:S37-40.

7. MacLaughlin HL, Cook SA, Kariyawasam D, et al. Nonrandomized trial of weight loss with orlistat, nutrition education, diet and exercise in obese patients with CKD: 2-year followup. Am J Kidney Dis. 2010;55(1):69-76.

8. Kälble T, Lucan M, Nicita G, et al. EAU guidelines on renal transplantation. Eur Urol. 2005;47(2):156-66.

9. Hasse J. Pretransplant obesity: a weighty issue affecting transplant candidacy and outcomes. Nutr Clin Pract. 2007;22(5):494-504.

10. Weiss $\mathrm{H}$, Nehoda $\mathrm{H}$, Labeck B, et al. Organ transplantation and obesity: evaluation, risks and benefits of therapeutic strategies. Obes Surg. 2000;10(5):465-9

11. Kokot F, Więcek A, Adamczak M, et al. Pathophysiological role of leptin in patients with chronic renal failure, in kidney transplant patients, in patients with essential hypertension, and in pregnant women with preeclampsia. Artific Organs. 1999;23(1):70-4.

12. Pischon T, Sharma AM. Obesity as a risk factor in renal transplant patients. Nephrol Dial Transpl. 2001;16(1):14-7.

13. Hakeem AR, Cockbain AJ, Raza SS, et al. Increased morbidity in overweight and obese liver transplant recipients: a single-center experience of 1325 patients from the United Kingdom. Liver Transpl. 2013;19(5):551-62.

14. Gloy VL, Briel M, Bhatt DL, et al. Bariatric surgery versus non-surgical treatment for obesity: a systematic review and meta-analysis of randomised controlled trials. BMJ. 2013;347:f5934.

15. Tichansky DS, Madan AK. Laparoscopic Roux-en-Y gastric bypass is safe and feasible after orthotopic liver transplantation. Obes Surg. 2005;15(10):1481-6.

16. Myers JA, Clifford JC, Sarker S, et al. Quality of life after laparoscopic adjustable gastric banding using the Baros and Moorehead-Ardelt Quality of Life Questionnaire II. JSLS J Soc Laparoendosc Surg. 2006;10(4):414.

17. Rogers CC, Alloway RR, Alexander JW, et al. Pharmacokinetics of mycophenolic acid, tacrolimus and sirolimus after gastric bypass surgery in end-stage renal disease and transplant patients: a pilot study. Clin Transplant. 2008;22(3):281-91.

18. Curran SP, Famure O, Li Y, et al. Increased recipient body mass index is associated with acute rejection and other adverse outcomes after kidney transplantation. Transplantation. 2014;97(1):64-70.

19. Viscido G, Gorodner V, Signorini FJ, et al. Sleeve gastrectomy after renal transplantation. Obes Surg. 2018;28(6):1587-94.

20. Lee CM, Cirangle PT, Jossart GH. Vertical gastrectomy for morbid obesity in 216 patients: report of two-year results. Surg Endosc. 2007:21(10):1810-6.

21. Leyba JL, Aulestia SN, Llopis SN. Laparoscopic Roux-en-Y gastric bypass versus laparoscopic sleeve gastrectomy for the treatment of morbid obesity. A prospective study of 117 patients. Obes Surg. 2011;21(2):212-6.

22. Trastulli S, Desiderio J, Guarino S, et al. Laparoscopic sleeve gastrectomy compared with other bariatric surgical procedures: a systematic review of randomized trials. Surg Obes Relat Dis. 2013;9(5):816-29.

23. Khoraki J, Katz MG, Funk LM, Campos GM, et al. Feasibility and outcomes of laparoscopic sleeve gastrectomy after solid organ transplantation. Surg Obes Relat Dis. 2016;12(1):75-83. 
24. Young MT, Gebhart A, Phelan MJ, et al. Use and outcomes of laparoscopic sleeve gastrectomy vs laparoscopic gastric bypass: analysis of the American College of Surgeons NSQIP. J Am Coll Surg. 2015;220(5):880-5.

25. Hutter MM, Schirmer BD, Jones DB, et al. First report from the American College of Surgeons-Bariatric Surgery Center Network: laparoscopic sleeve gastrectomy has morbidity and effectiveness positioned between the band and the bypass. Ann Surg. 2011;254(3):410.

26. Jakob T, Cal P, Deluca L, et al. Shorter than 24-h hospital stay for sleeve gastrectomy is safe and feasible. Surg Endosc. 2016:30(12):5596-600.

27. Lin MY, Tavakol MM, Sarin A, et al. Laparoscopic sleeve gastrectomy is safe and efficacious for pretransplant candidates. Surg Obes Relat Dis. 2013;9(5):653-8

28. Lin MY, Tavakol MM, Sarin A, et al. Safety and feasibility of sleeve gastrectomy in morbidly obese patients following liver transplantation. Surg Endosc. 2013;27(1):81-5.

29. Alexander JW, Goodman HR, Gersin K, et al. Gastric bypass inmorbidly obese patients with chronic renal failure and kidney transplant. Transplantation. 2004;78(3):469-74.

30. Golomb I, Winkler J, Ben-Yakov A, et al. Laparoscopic sleeve gastrectomy as a weight reduction strategy in obese patients after kidney transplantation. Am J Transplant. 2014;14(10):2384-90.
31. Kim Y, Jung AD, Dhar VK, et al. Laparoscopic sleeve gastrectomy improves renal transplant candidacy and posttransplant outcomes in morbidly obese patients. Am J Transplant. 2018;18(2):410-6.

32. Navarro-Díaz M, Serra A, Romero R, et al. Effect of drastic weight loss after bariatric surgery on renal parameters in extremely obese patients: longterm follow-up. J Am Soc Nephrol. 2006;17(12 suppl 3):S213-217.

33. Elli EF, Gonzalez-Heredia R, Sanchez-Johnsen L, et al. Sleeve gastrectomy surgery in obese patients post-organ transplantation. Surg Obes Relat Dis. 2016;12(3):528-34

34. Fernández-Fresnedo G, Plaza JJ, Sánchez-Plumed J, et al. Proteinuria: a new marker of long-term graft and patient survival in kidney transplantation. Nephrol Dial Transplant. 2004;19(3):47-51.

\section{Publisher's Note}

Springer Nature remains neutral with regard to jurisdictional claims in published maps and institutional affiliations.
Ready to submit your research? Choose BMC and benefit from:

- fast, convenient online submission

- thorough peer review by experienced researchers in your field

- rapid publication on acceptance

- support for research data, including large and complex data types

- gold Open Access which fosters wider collaboration and increased citations

- maximum visibility for your research: over $100 \mathrm{M}$ website views per year

At BMC, research is always in progress.

Learn more biomedcentral.com/submissions 